\title{
Genetic Consequences of Multiple Translocations of the Banded Hare-Wallaby in Western Australia
}

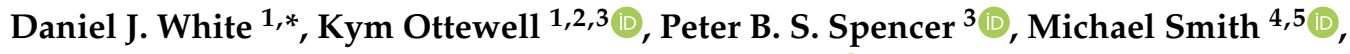 \\ Jeff Short $^{3,6}$, Colleen Sims ${ }^{2}$ and Nicola J. Mitchell ${ }^{1}$ (D) \\ 1 School of Biological Sciences, The University of Western Australia, 35 Stirling Hwy, Crawley, \\ Perth, WA 6009, Australia; kym.ottewell@dbca.wa.gov.au (K.O.); nicola.mitchell@uwa.edu.au (N.J.M.) \\ 2 Biodiversity and Conservation Science, Department of Biodiversity, Conservation and Attractions, \\ 17 Dick Perry Avenue, Kensington, Perth, WA 6151, Australia; colleen.sims@dbca.wa.gov.au \\ 3 Environmental and Conservation Sciences, Murdoch University, 90 South Street, Murdoch, \\ Perth, WA 6150, Australia; P.Spencer@murdoch.edu.au (P.B.S.S.); \\ jeff@wildliferesearchmanagement.com.au (J.S.) \\ 4 The Australian Wildlife Conservancy, P.O. Box 8070 Subiaco East, Perth, WA 6008, Australia; \\ Michael.Smith@australianwildlife.org \\ 5 Ecosystem Restoration and Intervention Ecology Research Group, School of Biological Sciences, \\ The University of Western Australia, 35 Stirling Highway, Crawley, Perth, WA 6009, Australia \\ 6 Wildlife Research and Management Pty Ltd., P.O. Box 1360, Kalamunda, WA 6926, Australia \\ * Correspondence: daniel.white@uwa.edu.au; Tel.: +61-8-6488-1967
}

Received: 9 October 2020; Accepted: 24 November 2020; Published: 27 November 2020

\begin{abstract}
Many Australian mammal species now only occur on islands and fenced mainland havens free from invasive predators. The range of one species, the banded hare-wallaby (Lagostrophus fasciatus), had contracted to two offshore islands in Western Australia. To improve survival, four conservation translocations have been attempted with mixed success, and all occurred in the absence of genetic information. Here, we genotyped seven polymorphic microsatellite markers in two source (Bernier Island and Dorre Island), two historic captive, and two translocated L. fasciatus populations to determine the impact of multiple translocations on genetic diversity. Subsequently, we used population viability analysis (PVA) and gene retention modelling to determine scenarios that will maximise demographic resilience and genetic richness of two new populations that are currently being established. One translocated population (Wadderin) has undergone a genetic bottleneck and lost $8.1 \%$ of its source population's allelic diversity, while the other (Faure Island) may be inbred. We show that founder number is a key parameter when establishing new L. fasciatus populations and 100 founders should lead to high survival probabilities. Our modelling predicts that during periodic droughts, the recovery of source populations will be slower post-harvest, while $75 \%$ more animals_-about 60 individuals - are required to retain adequate allelic diversity in the translocated population. Our approach demonstrates how genetic data coupled with simulations of stochastic environmental events can address central questions in translocation programmes.
\end{abstract}

Keywords: genetic diversity; population viability analysis; allele retention; translocation; conservation management; threatened marsupial; remnant

\section{Introduction}

Translocation, the anthropogenic movement of a group of organisms from one location to another, is an increasingly necessary tool for conservation management [1]. Conservation translocations take many forms (reintroductions, reinforcements, genetic rescue, assisted colonisation) and in all cases should be carefully planned, as they are costly and their success is hard to predict [2-7]. For example, in 
fauna translocations, animals may be naïve to predators at translocation sites $[6,8]$, and the harvesting of source populations may disrupt existing social dynamics [9-11]. Nevertheless, translocations are often the only option outside of ex situ conservation, to spread demographic risk and prevent extinctions [12-14].

As translocated populations often arise from a small number of founders, they risk losing genetic diversity via bottlenecks and/or genetic drift, and inbreeding depression can occur due to mating between related individuals [15]. It is therefore important to quantify the genetic diversity in source populations in order to manage these risks and to increase the evolutionary potential of translocated populations [7,16-19]. Individual-based population viability analysis modelling is a powerful tool for making predictions about potential outcomes of various translocation scenarios and can be used to optimise inherent, and often sensitive, trade-offs $[18,20]$. The incorporation of genetic data into population viability modelling is an important component of conservation decision making, and there has been a marked uptake of these types of analyses for Australian mammals [4,20-23].

Australia has the world's highest rate of mammal extinction [24]. Since European colonisation in 1788, 29 species have gone extinct and the western long-beaked echidna (Zaglossus bruijnii) is now extinct in Australia, equating to a rate of loss of around 0.13 species per year [24]. Major threats include predation from exotic introduced pests, in particular the European red fox (Vulpes vulpes) and feral cat (Felis catus), as well as habitat degradation. Habitat degradation includes both the loss of habitat and habitat fragmentation, both of which can exacerbate predation issues. In addition, smallto medium-sized mammals within a critical weight range (35-5500 g) are more prone to extinction than those outside this range [25-28]. For many of the endemic mammals of Australia that remain, their distributions have contracted to isolated populations, including offshore islands that remain feral predator free. To compound matters, climate change increases the risks of starvation, drought stress, and hyperthermia $[29,30]$. Accordingly, it is widely agreed that interventions are essential to secure Australia's remaining mammal diversity [24].

The banded hare-wallaby, Lagostrophus fasciatus, is a medium-sized (approx. $1700 \mathrm{~g}$ ), critical weight range herbivorous and nocturnal macropod, the sole member of the Lagostrophinae sub-family. It is currently listed as Vulnerable by the IUCN and under Australia's environmental legislation (the Environment Protection and Biodiversity Conservation Act). Their pre-European range stretched from the coast of central Western Australia to southern South Australia, but the species now survives only in the Shark Bay region of Western Australia on Bernier Island (4267 ha) and Dorre Island (5163 ha) (Figure 1a). The last recorded sighting on the mainland was in 1906 [31]. A 2016 survey suggested there were 2790 individuals on Bernier Island and 2440 individuals on Dorre Island [32], however, populations cycle through boom and bust phases, triggered by rainfall and drought, respectively, and may be reduced by as much as $75 \%$ before subsequent recovery $[33,34]$. These small island populations are expected to have low genetic diversity, which could be further reduced if used as source populations for conservation translocations. 


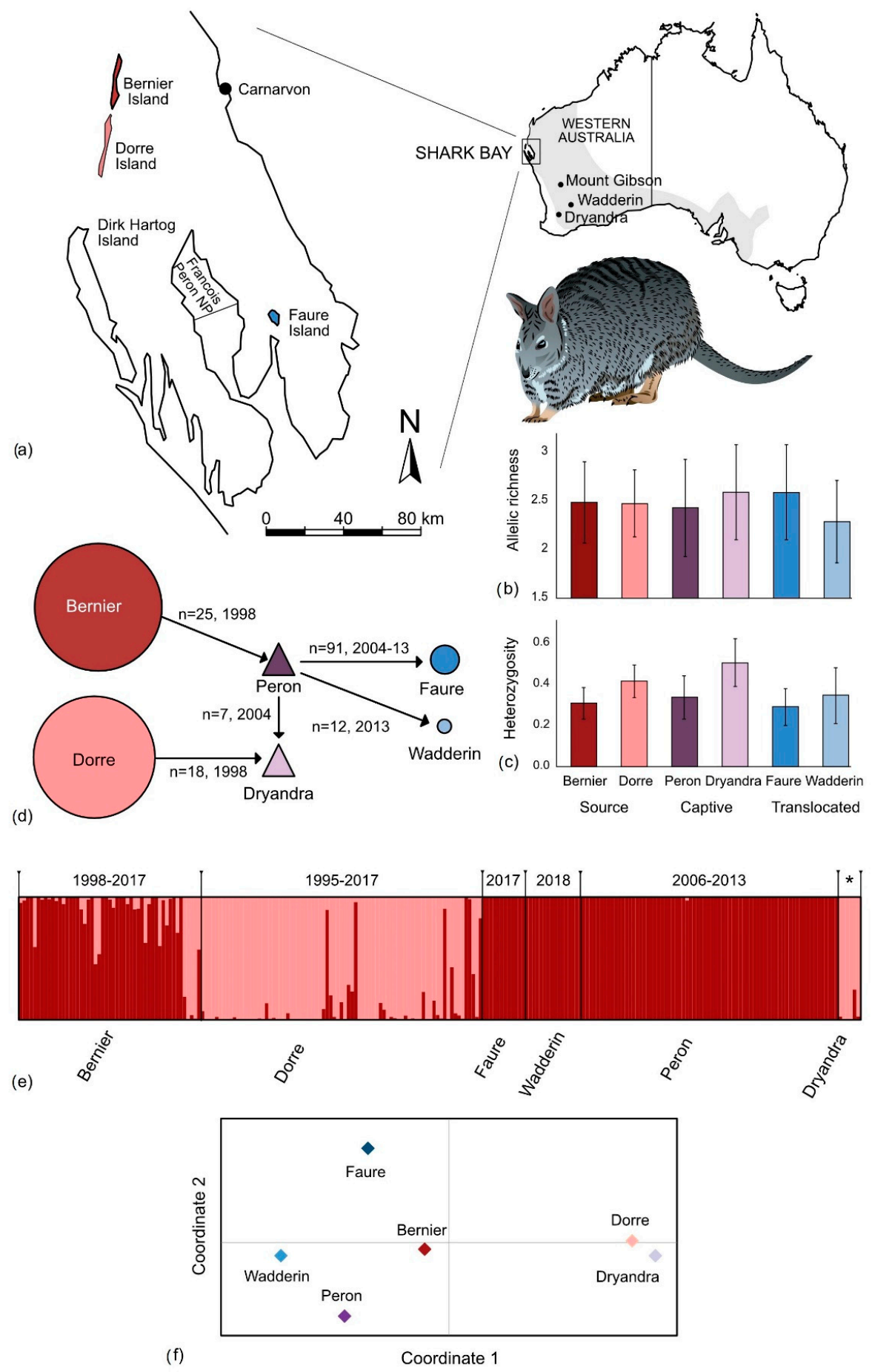

Figure 1. (a) Distribution of L. fasciatus in Western Australia (inset shows the approximate historical distribution); (b,c) measures of genetic diversity based on seven microsatellite markers; (d) translocation history (failed translocations not shown). Two recent translocations to Mt. Gibson and Dirk Hartog Island are underway; (e) STRUCTURE analysis of the two remnant wild populations (Bernier and Dorre Islands), two translocated populations (Faure Island and Wadderin), and two historic captive breeding populations (Peron Captive Breeding Centre (CBC) and Dryandra). Sampling periods are indicated at top of plot; * sampling period for Dryandra is 1999-2002; (f) population-level principal coordinates analysis based on genetic distance. The first two axes explain 91.6 of the variation. The L. fasciatus image was designed by Creazilla (creazilla.com). 
Since 1974, four translocations of L. fasciatus have been attempted, and two captive breeding colonies have been established but since discontinued (Figure 1d). The captive colony at Peron Captive Breeding Centre (hereafter Peron CBC) was managed by the Western Australian Department of Biodiversity, Conservation and Attractions (DBCA), and was sourced from Bernier Island. In contrast, a captive breeding colony at Dryandra was sourced from Dorre Island. Two translocation attempts were unsuccessful—specifically the movement of 21 animals from Dorre Island to southern Dirk Hartog Island from 1974 to 1978, and a movement of 18 animals from the Peron CBC to Francois Peron National Park in 2001. The failure of these translocations was attributed to predation by feral cats, drought (Dirk Hartog Island translocation), and the impact of livestock [35-37]. The two successful translocations were each founded from the Peron CBC, with 91 individuals released onto Faure Island between 2004 and 2013, and 12 individuals into Wadderin Sanctuary in 2013. Faure Island is a 4561-hectare island in Shark Bay managed by the Australian Wildlife Conservancy (AWC) where all feral predators and livestock have been removed and was reported to support a population size of approximately 300 in 2017 [38]. Wadderin Sanctuary on the mainland (Figure 1d) is a 430-hectare predator-free enclosure managed by a community group [39] and now holds approximately 30 animals [40].

Currently, two new populations of L. fasciatus are being established. From 2017 to 2018, a population of L. fasciatus was reintroduced to a 7832 ha safe haven (a fenced area from which introduced predators have been removed) at Mount Gibson Wildlife Sanctuary. A total of 119 individuals were translocated to Mt. Gibson from Bernier $(n=40)$, Faure $(n=19)$ and Dorre $(n=60)$ Islands. In 2017, a translocation programme began for L. fasciatus to Dirk Hartog Island (58,640 ha), forming part of DBCA's "Return to 1616" project following the removal of exotic predators and herbivores [41]. Fifty-six individuals from both Bernier and Dorre Islands were proposed to be moved over 3 years (total $n=112$ ). In this study, we aim to determine how the translocation history of L. fasciatus has affected the genetic health of all extant populations, particularly as serial translocations via intermediary captive populations have led to the possibility of genetic bottlenecks. We use genetic and population viability analysis models to explore the impact on source populations of concurrent harvesting scenarios and how the retention of genetic diversity can be maximised, and we predict growth rates and genetic diversity of the new Dirk Hartog Island and Mount Gibson populations. Most analyses are conducted under a baseline assumption of regular drought cycles that reduce reproductive success and survivorship, and we test the sensitivity of our results to both reduced and increased drought frequencies, as both scenarios are possible under climate change [42].

\section{Materials and Methods}

\subsection{Tissue Samples}

Ear biopsies were sampled over 19 years, from 1998 to 2017, from six locations: Dorre Island $(n=79)$, Bernier Island $(n=51)$, Faure Island $(n=10)$, the Peron CBC $(n=73)$, the Return to Dryandra Captive Facility (hereafter Dryandra, $n=6)$, and Wadderin Sanctuary $(n=17)$ (Figure 1d). All available L. fasciatus samples ( $n=236$, Spreadsheet S1) were analysed.

\subsection{DNA Extraction and Nuclear Microsatellite Amplification}

Genomic DNA was extracted from ear tissue using a standard "salting out" protocol [43]. Ten microsatellite loci were initially amplified using primers derived from the tammar wallaby (Macropus eugenii; Me14, Me17; [44]), yellow-footed rock-wallaby (Petrogale xanthopus; Y105, Y175, Y151, Y148; [45]), and allied rock-wallaby (P. assimilis; Pa593, Pa297, Pa385, Pa55; [46]). Briefly, for samples prior to 2016, polymerase chain reactions (PCRs) were carried out for individual microsatellite primers in a total volume of $30 \mu \mathrm{L}$ with $100 \mathrm{ng}$ DNA, 1 X PCR buffer, $400 \mu \mathrm{M}$ of dNTPs, $2 \mathrm{mM} \mathrm{MgCl}_{2}, 0.2 \mu \mathrm{M}$ of each primer, and $0.825 \mathrm{U}$ Taq or, after 2016, in three PCR multiplexes using the Qiagen Multiplex PCR kit for a total volume of 7.5 $\mu \mathrm{L}$ per multiplex with 5-10 ng DNA, 1X Qiagen buffer, $0.2 \mu \mathrm{M}$ primer mix, and water (Table S1). Fluorescently labelled DNA fragments were separated using an ABI373x1 
capillary sequencer (Applied Biosystems, Foster City, CA, USA) and scored manually with the aid of GENEMARKER software (v1.5, Soft Genetics, State College, PA, USA). Allele size was determined by co-running a Genescan500 standard (Applied Biosystems, Melbourne, Australia). Data were checked for input errors and duplicate genotypes using the Excel Microsatellite Toolkit add-in [46]. Deviations from Hardy-Weinberg equilibrium and linkage disequilibria were tested using GENEPOP v4.1.4 [47]. For markers with fewer than five alleles, a complete enumeration algorithm was used to estimate the exact $p$ value; and for markers with five or more alleles, the Markov chain algorithm of Guo and Thompson [48] was used to generate an unbiased estimate of the exact $p$ value. The presence of any null alleles was tested with MICROCHECKER v2.2.3 [49].

\subsection{Statistical Analyses of Genetic Data}

The programme STRUCTURE v2.3.4 [50] was used to estimate the number of genetically distinct populations and to assign individuals to populations. STRUCTURE uses a Bayesian clustering method to assign individuals to one of $\mathrm{k}$ populations and to estimate the degree of inter-population admixture. While some assumptions made by the software will likely not be met by the island populations in our system, such as the distribution of genotypes under Hardy Weinberg Equilibrium (HWE) and marker linkage equilibria, this approach still provides a useful assessment of population genetic divergence. Our models assumed no admixture between locations, but since in some cases locations represent recently sub-sampled source populations, and therefore could have shared allele frequencies, we ran models that assumed either correlated or uncorrelated allele frequencies between groups for comparison. After preliminary assessment of convergence times for the Monte Carlo Markov chain, a burn-in period of 100,000 steps was chosen, followed by 1,000,000 steps of the chain. To estimate $k$, four replicate runs at each value of $\mathrm{k}$ from 1 to 8 were performed, and the most likely value was estimated from the plot of $\ln \operatorname{Pr}(X \mid k)$ vs. $k$, as well as from Evanno's method [51] which plots $\Delta \mathrm{k}$ (a second order rate of change of $\ln \operatorname{Pr}(X \mid k))$ vs. $k$, using CLUMPAK beta version [52]. STRUCTURE figures were generated using DISTRUCT v1.1 [53] in CLUMPAK [52]. To assess genetic similarity between populations using an approach that does not rely on the same biological assumptions, a principal coordinates analysis was conducted based on genetic distance, run in GENALEX v6.503 [54,55]. The level of genetic differentiation among all populations was determined by estimating pairwise $\mathrm{F}_{\mathrm{ST}}$ and Jost's Dest, also in GENALEX v6.503. Probabilities were calculated as the proportion of times the observed data generated values greater than values generated from 999 random permutations.

Standard genetic diversity metrics, including mean number of individuals per marker, mean number of alleles per marker, and observed and expected heterozygosities, were estimated for each sampling site, in GENALEX v6.503. Allelic richness, a measure of allelic diversity that controls for variable sample size, was estimated in HP-RARE [56] based on rarefaction to ten individuals. As marker Me17 was monomorphic except for one individual in the Faure population, in which it was homozygous for the alternate allele, allelic richness was calculated with and without this marker. Population inbreeding coefficients were measured using Wright's $\mathrm{F}_{\text {IS }}$ in GENEPOP v4.1.4 [47]. Expected and observed heterozygosities, allelic richness, and FIS measurements were made for source populations separated into year cohorts. We estimated the genetic effective population size (Ne) using the linkage disequilibrium method on populations with a sample size of 25 or more [57-59], excluding singleton alleles (those that occur in one copy in one heterozygote) to prevent an upward bias in $\mathrm{Ne}$ estimation, as implemented in NeESTIMATOR v2.1 [60].

To assess whether any of the managed or natural populations underwent a genetic bottleneck, we compared the heterozygote distribution for each marker with the number of alleles for each population in BOTTLENECK v1.2 [61], using the two-phase substitution model with default proportions of the infinite alleles and single stepwise mutation models. A one-tailed Wilcoxon signed-rank test was used to estimate the likelihood that the observed data deviate from what is expected under mutation-drift equilibrium, the most appropriate test with fewer than 20 loci [62,63]. We also reported whether the 
allele frequency distribution deviated from an L-shaped mode, which can be a qualitative assessment of whether a population has passed through a genetic bottleneck [64].

Queller and Goodnight's [65] estimator was used to measure the mean pairwise relatedness within each population, as an indicator of genotype diversity and identity by descent within source populations. Whether the mean pairwise relatedness of a population was statistically different from 0 (defined as mean pairwise relatedness across the entire data set) was estimated by randomly permuting the data in the population pairwise matrix 999 times, and determining the proportion of permutations that gave a relatedness value greater than the observed value, as calculated in GENALEX v6.503.

\subsection{Population Modelling}

To estimate the number of founders needed to retain low-frequency alleles within newly established populations, scenarios were simulated in ALLELERETAIN v1.1 [66,67] implemented in R v3.6.2 [68]. ALLELERETAIN is an individual-based model that simulates population growth using a user-defined suite of parameters based on life-history traits. It estimates the probability of retention of selectively neutral alleles in founder populations over generations, with the starting frequency of these alleles set by the user. We were interested in assessing the impacts of translocating individuals of varying founder group size $(\mathrm{N})$ on allele retention. To do this, we tested founder $\mathrm{N}$ values from 20 to 200 in increments of 20 individuals with allele frequency set to 0.05 . We then repeated each scenario but considered the translocation to have occurred during a drought year. This was simulated by setting the initial survival after translocation to 0.4 and excluding reproduction for the first breeding cycle. For all simulations, we assumed that one L. fasciatus breeding cycle lasts 9 months [69]. Details and justification of the demographic parameters used in the model are provided in Table 1 and Table S2.

Table 1. Life history parameters used for L. fasciatus population modelling in VORTEX and ALLELERETAIN. Parameter values were obtained from data in $[33,34,41,70]$ and refined by C.S. and J.S. Where a parameter is not listed, defaults are used. V: VORTEX; A: ALLELERETAIN; EV: environmental variation; BHW: banded hare wallaby; DDR: density-dependent reproduction function.

\begin{tabular}{|c|c|c|}
\hline Life History Parameter & Value & Used in \\
\hline \multicolumn{3}{|l|}{ Species description } \\
\hline Inbreeding depression & & $\mathrm{V}$ \\
\hline Lethal equivalents & 3.14 & $\mathrm{~V}$ \\
\hline$\%$ due to recessive lethal & 50 & $\mathrm{~V}$ \\
\hline EV concordance of reproduction and survival & 0.5 & $\mathrm{~V}$ \\
\hline EV correlation among populations & $0.5-0.8$ & $\mathrm{~V}$ \\
\hline \multicolumn{3}{|l|}{ Reproductive system } \\
\hline Reproductive system & polygynous & $\mathrm{V} / \mathrm{A}$ \\
\hline Duration of breeding cycle in days & 274 & $\mathrm{~V} / \mathrm{A}$ \\
\hline Age of first offspring for females/males & 9 months/18 months & $\mathrm{V} / \mathrm{A}$ \\
\hline Maximum age of reproduction & 8 years & $\mathrm{V} / \mathrm{A}$ \\
\hline Maximum lifespan & 10 years & $\mathrm{V} / \mathrm{A}$ \\
\hline Maximum number of broods per breeding cycle & 1 & $\mathrm{~V} / \mathrm{A}$ \\
\hline Maximum number of progeny per brood & 1 & $\mathrm{~V} / \mathrm{A}$ \\
\hline Mean female number of progeny per breeding cycle & 1 & A \\
\hline Mean male lifetime reproductive success $( \pm \mathrm{SD})$ & $7 \pm 3$ & A \\
\hline Sex ratio at birth & 50 & $\mathrm{~V} / \mathrm{A}$ \\
\hline \multicolumn{3}{|l|}{ Reproductive rates } \\
\hline$\%$ adult females breeding & $90 \%$ with DDR & $\mathrm{V}$ \\
\hline EV in \% breeding & 18 & $\mathrm{~V}$ \\
\hline \multicolumn{3}{|l|}{ Distribution of broods per breeding cycle } \\
\hline 0 broods & 0 & $\mathrm{~V}$ \\
\hline 1 brood & $100 \%$ & $\mathrm{~V}$ \\
\hline \multicolumn{3}{|l|}{ Number of offspring per female brood } \\
\hline 1 offspring & $100 \%$ & $\mathrm{~V}$ \\
\hline
\end{tabular}


Table 1. Cont.

\begin{tabular}{|c|c|c|}
\hline Life History Parameter & Value & Used in \\
\hline $\begin{array}{c}\text { Mate monopolisation } \\
\% \text { males in breeding pool } \\
\% \text { males successfully siring offspring } \\
\text { Mortality rates }\end{array}$ & $\begin{array}{l}85 \\
63\end{array}$ & $\begin{array}{l}\mathrm{V} \\
\mathrm{V}\end{array}$ \\
\hline $\begin{array}{c}\text { Females } \\
\text { Mortality age } 0 \text { to } 1( \pm \mathrm{SD}) \\
\text { Annual mortality after age } 1( \pm \mathrm{SD})\end{array}$ & $\begin{array}{c}40( \pm 10) \\
10( \pm 3)\end{array}$ & $\begin{array}{l}\mathrm{V} / \mathrm{A} \\
\mathrm{V} / \mathrm{A}\end{array}$ \\
\hline $\begin{array}{c}\text { Males } \\
\text { Mortality age } 0 \text { to } 1( \pm \mathrm{SD}) \\
\text { Annual mortality after age } 1( \pm \mathrm{SD})\end{array}$ & $\begin{array}{c}40( \pm 10) \\
10( \pm 3)\end{array}$ & $\begin{array}{l}\text { V/A } \\
\text { V/A }\end{array}$ \\
\hline $\begin{array}{c}\text { Catastrophes } \\
\text { Number of types of catastrophes } \\
\text { Frequency } \\
\text { Severity }\end{array}$ & $\begin{array}{l}1 \text { (drought) } \\
1 \text { in } 6.25 \text { calendar years }^{\mathrm{a}} \\
50 \% \text { reduction in survival } \\
\text { and reproduction }\end{array}$ & $\begin{array}{l}\mathrm{V} \\
\mathrm{V} \\
\mathrm{V}\end{array}$ \\
\hline $\begin{array}{l}\text { Initial population size } \\
\text { Bernier } \\
\text { Dorre } \\
\text { Faure }\end{array}$ & $\begin{array}{c}2000 \\
2000 \\
300\end{array}$ & $\begin{array}{l}\text { V/A } \\
\text { V/A } \\
\text { V/A }\end{array}$ \\
\hline $\begin{array}{c}\text { Carrying capacity, } K(S D \text { due to } E V) \\
\text { Bernier } \\
\text { Dorre } \\
\text { Faure } \\
\text { DHI } \\
\text { Mt. Gibson }\end{array}$ & $\begin{array}{c}3000(300) \\
3000(300) \\
1000(100) \text { or } 3000(300) \\
(1000) \\
5000(500)\end{array}$ & $\begin{array}{l}\text { V/A } \\
\text { V/A } \\
\text { V/A } \\
\text { V/A } \\
\text { V/A }\end{array}$ \\
\hline $\begin{array}{l}\text { Genetic management } \\
\text { Number of neutral loci to be modelled } \\
\text { Initial minor allele frequency }\end{array}$ & $\begin{array}{c}7 \text { empirical, } 1 \text { simulated } \\
0.05\end{array}$ & $\begin{array}{l}\mathrm{V} \\
\mathrm{A}\end{array}$ \\
\hline $\begin{array}{l}\text { Scenario settings } \\
\text { No. replicates } \\
\text { No. years }\end{array}$ & $\begin{array}{c}1000 / 100 \\
50 \text { calendar years }\end{array}$ & $\begin{array}{l}\text { V/A } \\
\text { V/A }\end{array}$ \\
\hline
\end{tabular}

To estimate the impact of current translocation programmes on extinction probabilities and heterozygosities of the newly established L. fasciatus populations and the source populations, population viability analysis (PVA) simulations were run in VORTEX v10.17.2 [71,72]. VORTEX is an individual-based model that uses Monte Carlo simulations to estimate how factors intrinsic to individuals within populations alter growth rates, birth rates and extinction probabilities [72]. Initially, we developed a baseline PVA for a closed population with a starting $\mathrm{N}$ of 2000 individuals and a carrying capacity of 3000, where droughts at an average frequency of 1 in 6.25 calendar years reduced survival and reproduction by $50 \%$, similar to empirical observations [33,34]. Although there is no empirical evidence for inbreeding depression, we included it in our models as there has been as yet no formal effort to detect it and populations do regularly pass through extreme population bottlenecks $[33,34]$. However, as populations appear to persist through these bottlenecks without obvious signs of depression, we halved the default number of lethal equivalents. Other island populations of marsupials are known to survive small effective population sizes and high levels of inbreeding [73]. Baseline model parameters are provided in Table 1 and Table S3.

Various translocation scenarios (each of 1000 replicates) were then simulated that tested the number of founders and source populations needed to maximise genetic diversity and population growth for a translocation programme that, due to the logistical cost to the management agency, runs for a maximum of two years (Table 2). Bernier Island was chosen for single source population 
translocations for two reasons. Firstly, as this population is smaller in size and has lower genetic diversity, it represents a conservative, worst case scenario, and secondly, this island is easier to access due to protected landing beaches. To quantify the impact of drought on translocation success, the best performing of these scenarios was re-run with both increased and decreased drought frequencies, and with no drought. Finally, a case study (scenario 8) was simulated based on the recent movements of L. fasciatus from Bernier and Dorre Islands to Dirk Hartog Island, and from Bernier, Dorre, and Faure Islands to the Mount Gibson Wildlife Sanctuary. Although the carrying capacity of Faure Island could theoretically be similar to Bernier and Dorre Islands (predicted here to be 3000) based on land area, there is currently no empirical evidence for this and the census population size remains well below 1000 . We therefore tested two different carrying capacities for Faure Island, 3000 and a more conservative 1000. To further assess the impact of drought cycles in translocation planning, both the current and post-drought estimates of source population sizes were used as inputs in case study models.

Table 2. Hypothetical and case study translocation scenarios * examined using population viability analyses.

\begin{tabular}{|c|c|c|}
\hline Target Population & Scenario & Description \\
\hline \multirow{5}{*}{ Dirk Hartog Island } & 1 & One translocation from Bernier Island in year 1 \\
\hline & 2 & $\begin{array}{l}\text { Individuals translocated from Bernier Island only, half in each } \\
\text { of first two years }\end{array}$ \\
\hline & 3 & $\begin{array}{l}\text { Individuals translocated from Bernier and Dorre Islands, half } \\
\text { from one island in year } 1 \text { and half from other island in year } 2\end{array}$ \\
\hline & 4 & $\begin{array}{l}\text { Individuals translocated from Bernier and Dorre Islands, half } \\
\text { from each island in year } 1\end{array}$ \\
\hline & $5-7$ & $\begin{array}{l}\text { Best performing scenario from } 1 \text { to } 4 \text {, with drought frequencies } \\
\text { of no drought, } 1 \text { in } 10 \text { years, and } 1 \text { in } 5 \text { years }\end{array}$ \\
\hline $\begin{array}{l}\text { Dirk Hartog Islandand Mount } \\
\text { Gibson Wildlife Sanctuary }\end{array}$ & 8 & $\begin{array}{c}\text { To Dirk Hartog Island: six individuals from Bernier and six } \\
\text { from Dorre in BHW year 1; } 50 \text { from Bernier in BHW year 2; } 50 \\
\text { from Dorre in BHW year 3To Mount Gibson: } 23 \text { individuals } \\
\text { from Bernier, } 39 \text { from Dorre, and } 10 \text { from Faure in BHW year 1; } \\
37 \text { from Bernier, one from Dorre, and } 20 \text { from Faure in BHW } \\
\text { year } 3\end{array}$ \\
\hline
\end{tabular}

\section{Results}

\subsection{Marker Performance}

Of the ten microsatellite markers amplified, three were monomorphic in this species. The informativeness of the seven polymorphic markers varied, with the number of alleles ranging from two (Y175 and Me17) to eight (Pa593) (Table S4). Expected heterozygosity (mean \pm SE) ranged from $0.03 \pm 0.03$ (Me17), which was polymorphic in only one population, to $0.66 \pm 0.02$ (Pa593). The mean percentage of samples with missing genotype data across all populations ranged from $0.0 \%$ (markers Pa593, Me14 and Y105) to 5.1\% (marker Y148). Marker Y175 violated the Hardy-Weinberg equilibrium $(p<0.05)$ in three populations out of six. Analysis in MICROCHECKER suggested the unexpectedly high homozygote frequency was caused by a null allele in all three populations. The percentage of samples with missing genotype data for this marker ranged from $0.0 \%$ (Dryandra) to $12.3 \%$ (Peron CBC), with a mean of 3.8\%. After assessing the impact of null alleles on the estimation of global and pairwise FSTs in FreeNA [74], no significant differences were observed between estimates calculated with and without correcting for null alleles. Considering this, and the low number of markers, Y175 was retained for further analysis. 


\subsection{Genetic Diversity}

Structure analysis revealed that the most likely number of genetically distinct clusters of L. fasciatus is two $(\mathrm{k}=2$; Figure 1e), representing the two remnant wild populations on Bernier and Dorre Islands. There was very good agreement in results whether allele frequencies were assumed to be correlated or uncorrelated between locations, and the absolute probability for $\mathrm{k}=2$ was slightly greater for correlated allele frequencies. Of the contemporary translocated populations, Faure Island and Wadderin are predominantly of Bernier Island origin, with negligible genomic contribution from Dorre Island. Of the extinct captive populations, Peron CBC was an extension of Bernier Island, whereas Dryandra was predominantly of Dorre Island origin. A small amount of potential admixture was detected between Bernier and Dorre Islands. In total there are ten individuals (four from Bernier and six from Dorre) that have an $80 \%$ or more probability of assignment to the other source population. Principal coordinate analysis agreed with the STRUCTURE results (Figure 1f). Both pairwise FST and Jost's Dest measurements were similar $\left(\mathrm{F}_{\mathrm{ST}}=0.026, p<0.001\right.$; Dest $\left.=0.029, p<0.001\right)$, reflective of weak, significant divergence between the two parental populations. A summary of all pairwise FSTs is provided in Table S5, which shows that greatest distance exists between Bernier Island-derived populations and Dryandra (the sole Dorre Island-derived population). Pairwise relatedness analysis revealed that one source population (Bernier Island, $p<0.005$ ), one extinct captive population (Peron $\mathrm{CBC}, p<0.002$ ), and one contemporary translocated population (Wadderin, $p<0.014$ ) have relatedness values statistically greater than zero (Figure S1).

Overall, genetic diversity was low across all populations (mean expected heterozygosity, $\mathrm{HE}=0.34-0.45$ ). Of the source populations, Dorre Island exhibited higher heterozygosity and lower inbreeding than Bernier Island, although allelic richness was comparable. Dorre Island had one private allele (alleles present in one population only) for marker $\mathrm{Y} 105(\mathrm{q}=0.02)$, Faure Island had two (Pa593, q = 0.05; Me17, q = 0.10), and Peron CBC had one $(Y 148, q=0.01)$. When the two parental populations were compared only to each other, Dorre Island had four private alleles and Bernier Island had one. Diversity estimates within year cohorts for both Bernier and Dorre Islands showed a similar trend of higher than expected heterozygosities in the late 1990s, and lower than expected heterozygosities in more recent cohorts. Both expected heterozygosity and allelic richness have declined over the sampling period (Supplementary Figure S2). There were no significant differences in genetic variation between translocated and source populations except for Faure Island which showed a significant decrease in observed heterozygosity compared to Peron CBC using a one-tailed Wilcoxon signed-rank test $(p<0.05)$, and this island also indicated significant inbreeding due to non-random mating. Considering the two parental populations as one remnant $L$. fasciatus metapopulation, Faure has retained $93 \%$ of allelic diversity, while Wadderin has retained $87 \%$. Calculating allelic richness without marker Me17 increases its value in all populations, but Faure no longer has the highest allelic diversity (Table S6). Caution is needed when interpreting all diversity results, however, as sample sizes for diversity measurements were often very low and varied between sites and temporal data.

Estimates of effective population sizes in extant populations reflected overall diversity measurements (Table 3), as Dorre Island had the highest $\mathrm{Ne}$ in the 2016-2017 cohort $(\mathrm{Ne}=140$, $95 \%$ CI $29-\infty)$, which was $71 \%$ higher than for Bernier Island L. fasciatus sampled in the same period $(\mathrm{Ne}=82,95 \% \mathrm{CI} 12-\infty)$. Values of infinity for upper confidence limits arise from a lack of evidence for variation in the genetic characteristic which, in this case, is likely due to the small, homogeneous marker panel $[59,60]$. Our estimates of effective population size should therefore be considered cautiously and await confirmation with a more powerful dataset. 
Table 3. Population-level diversity metrics using seven polymorphic microsatellite markers.

\begin{tabular}{|c|c|c|c|c|c|c|c|c|c|}
\hline Population & $\mathrm{N}^{\mathrm{a}}$ & HWE $^{b}$ & NA & PA & AR ( \pm s.e.) & HE ( \pm s.e. $)$ & HO ( \pm s.e. $)$ & F $_{I S}( \pm$ s.e. $)$ & $\mathrm{Ne}(95 \% \mathrm{CI})$ \\
\hline Bernier Island (all) & 51 & $1 / 6$ & 20 & 0 & $2.47(0.15)$ & $0.36(0.09)$ & $0.30(0.08)$ & $0.14(0.05)$ & \\
\hline Bernier (1998) & 6 & & & & $\mathrm{n} / \mathrm{a}$ & $0.38(0.11)$ & $0.43(0.15)$ & $-0.06(0.17)$ & $\mathrm{n} / \mathrm{a}$ \\
\hline Bernier (2010-2011) & 9 & & & & $\mathrm{n} / \mathrm{a}$ & $0.34(0.10)$ & $0.23(0.07)$ & $0.31(0.10)$ & $\mathrm{n} / \mathrm{a}$ \\
\hline Bernier (2016-2017) & 33 & & & & $2.40(0.15)$ & $0.36(0.08)$ & $0.31(0.07)$ & $0.11(0.04)$ & $82(12, \infty)$ \\
\hline Dorre Island (all) & 79 & $2 / 6$ & 23 & 1 & $2.46(0.10)$ & $0.42(0.08)$ & $0.41(0.08)$ & $0.03(0.07)$ & \\
\hline Dorre (1995-1996) & 7 & & & & $\mathrm{n} / \mathrm{a}$ & $0.44(0.08)$ & $0.61(0.11)$ & $-0.39(0.07)$ & $\mathrm{n} / \mathrm{a}$ \\
\hline Dorre (1999-2000) & 8 & & & & $\mathrm{n} / \mathrm{a}$ & $0.45(0.09)$ & $0.45(0.09)$ & $0.00(0.07)$ & $\mathrm{n} / \mathrm{a}$ \\
\hline Dorre (2013) & 11 & & & & $2.41(0.29)$ & $0.42(0.08)$ & $0.43(0.09)$ & $0.01(0.08)$ & $\mathrm{n} / \mathrm{a}$ \\
\hline Dorre (2016-2017) & 52 & & & & $2.40(0.11)$ & $0.40(0.07)$ & $0.38(0.08)$ & $0.07(0.10)$ & $140(29, \infty)^{\mathrm{c}}$ \\
\hline Faure Island (2017) & 10 & $0 / 6$ & 18 & 2 & $2.57(0.40)$ & $0.39(0.08)$ & $0.29(0.09)$ & $0.36(0.14)$ & $\mathrm{n} / \mathrm{a}$ \\
\hline Wadderin (2018) & 17 & $1 / 5$ & 16 & 0 & $2.27(0.27)$ & $0.36(0.10)$ & $0.34(0.13)$ & $0.09(0.20)$ & $\mathrm{n} / \mathrm{a}$ \\
\hline Peron CBC (2006-2013) & 73 & $1 / 5$ & 19 & 1 & $2.41(0.15)$ & $0.36(0.10)$ & $0.33(0.10)$ & $0.08(0.08)$ & $20(7,57)$ \\
\hline \multirow[t]{2}{*}{ Dryandra (1999-2002) } & 6 & $0 / 6$ & 18 & 0 & $\mathrm{n} / \mathrm{a}$ & $0.40(0.08)$ & $0.50(0.12)$ & $-0.28(0.15)$ & $\mathrm{n} / \mathrm{a}$ \\
\hline & 236 & & & $\mu$ (土s.d.) & $2.34(0.13)$ & $0.39(0.02)$ & $0.37(0.08)$ & $0.07(0.21)$ & \\
\hline
\end{tabular}

N: number of samples; HWE: Hardy-Weinberg equilibrium; NA: total number of alleles; PA: private alleles; AR: allelic richness (rarefied to 10 individuals); HE: expected heterozygosity; HO: observed heterozygosity; FIS: inbreeding coefficient; Ne: effective population size. ${ }^{a}$ Diversity estimates for samples of size 10 or fewer should be treated with caution. ${ }^{b}$ Proportion of polymorphic markers that violate HWE at $p<0.05 ;^{\mathrm{c}}$ value obtained only with no critical minor allele frequency threshold. Heterozygosity metrics and inbreeding coefficients are also calculated for different time periods for Bernier and Dorre Islands, when at least five individuals were sampled for that time period. 
Combining samples from all years, only one source population, Dorre Island, had statistical support $(p=0.039)$ for passing through a genetic bottleneck (Table 4$)$. However, when Bernier and Dorre Islands were separated into year cohorts, both populations showed evidence of genetic bottlenecks in the earlier cohorts (1990s), and for Dorre Island also in 2013. Of the managed populations, Wadderin was the only population showing evidence of a genetic bottleneck (Table 4). Thirty individuals and 10 polymorphic loci are recommended to achieve power of at least 0.8 with the Wilcoxon signed-rank test however, so these results should be considered with caution. Both Wadderin and Peron CBC had an allele frequency distribution shifted towards more common alleles, consistent with a bottleneck, although this qualitative test requires at least 30 individuals and 10 to 20 polymorphic loci to be reliable [61].

Table 4. Results of two tests for a genetic bottleneck of source and translocated populations.

\begin{tabular}{|c|c|c|c|}
\hline \multirow{2}{*}{ Population (Time Period) } & \multirow{2}{*}{$n$} & \multicolumn{2}{|l|}{ Bottleneck Test } \\
\hline & & Wilcoxon (One-Tailed, H Excess) & Mode Shift \\
\hline Bernier Island (all) & 51 & 0.281 & No \\
\hline Bernier Island (2016/2017) & 33 & 0.500 & No \\
\hline Bernier Island (2010/2011) & 9 & 0.109 & Yes \\
\hline Bernier Island (1998) & 6 & 0.016 & Yes \\
\hline Dorre Island (all) & 79 & 0.039 & No \\
\hline Dorre Island (2016/2017) & 52 & 0.422 & No \\
\hline Dorre Island (2013) & 11 & 0.008 & Yes \\
\hline Dorre Island (1999/2000) & 8 & 0.008 & Yes \\
\hline Dorre Island $(1995 / 1996)$ & 7 & 0.016 & Yes \\
\hline Peron CBC (from Bernier; $t=25, y=1998$ ) & 73 & 0.219 & Yes \\
\hline $\begin{array}{l}\text { Dryandra (from Dorre and Peron CBC; } \\
\qquad t=25, y=1998)\end{array}$ & 6 & 0.578 & No \\
\hline $\begin{array}{l}\text { Faure Island (from Peron CBC; } t=91 \\
\qquad y=2004 \text { to 2013) }\end{array}$ & 10 & 0.281 & No \\
\hline $\begin{array}{l}\text { Wadderin (from Peron CBC; } \mathrm{t}=12 \text {, } \\
\qquad \mathrm{y}=2013 \text { ) }\end{array}$ & 17 & 0.031 & Yes \\
\hline
\end{tabular}

Integers represent $p$ values, with significant values in bold. $n$ : sample size; $\mathrm{t}$ : translocated population size; $\mathrm{y}$ : year of translocation. The two-phase mutation model of microsatellite evolution is assumed with a 70:30\% ratio of single stepwise mutation to infinite allele models. Year cohorts with fewer than five individuals were omitted from analyses. Estimates based on sample sizes of fewer than 30 should be considered tentative.

\subsection{Modelling Conservation Translocations}

In the absence of periodic droughts, ALLELERETAIN demonstrated the strongest increases in the probability of retaining low-frequency alleles when the founder population size approached 20, and began to plateau after 40 (Figure 2). Sixty founders are needed to retain $90 \%$ of alleles at a frequency of 0.05 , and 80 founders are needed to retain $95 \%$ of alleles (recommended thresholds) at a frequency of 0.05 . These numbers rose to 120 and 140 founders, respectively, when realistic impacts of drought were simulated. 


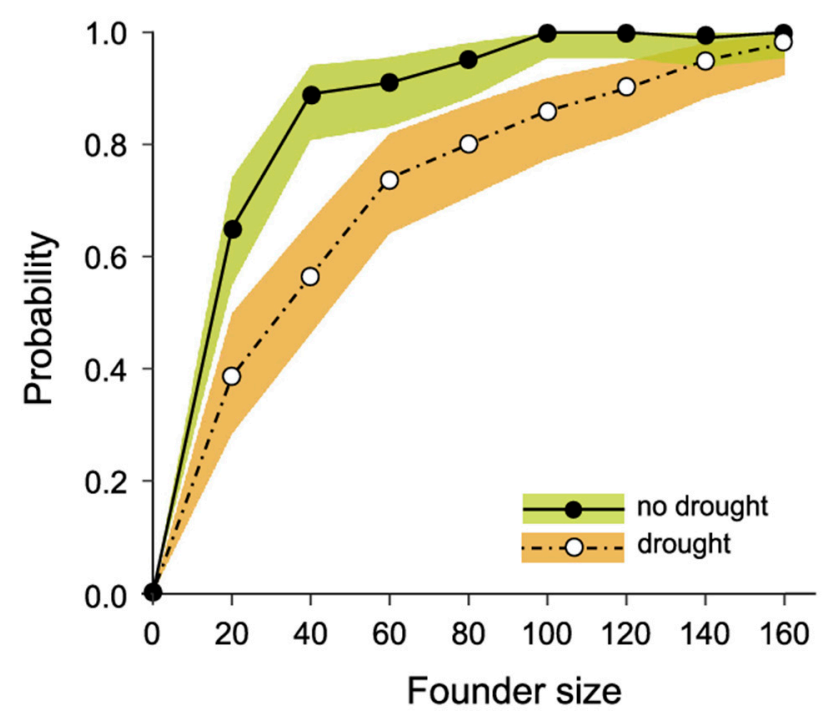

Figure 2. Probability of retaining a selectively neutral allele at a starting population frequency of 0.05 after 50 calendar years for translocated L. fasciatus populations with various founder sizes, with and without impacts of drought. Shaded ribbons represent $95 \%$ confidence intervals.

Population viability analysis modelling showed that when contrasting founder population sizes between 60 and 140, survival probabilities increase with increasing founder number until this relationship begins to asymptote from around 100 individuals (Table S7a-d). This level of harvesting also had limited impact on the source populations. Mixing the two source populations of Bernier and Dorre Islands increased heterozygosity in the translocated population, relative to only using founders from Bernier Island, and there was minimal impact of moving all individuals in one year versus splitting the translocation over two years (Table 5). Considering the additional logistical cost of a second year of translocation activities, the best scenario in terms of maximising survival probability, genetic diversity (heterozygosity and allelic diversity), and the final population size of the translocated population was to harvest the two source populations in one year (Scenario 4, Table 5).

Table 5. Viability of a translocated L. fasciatus population after 50 calendar years, testing four scenarios. One hundred individuals translocated in one or over two years, including a drought with a mean frequency of one every 6.25 calendar years. Carrying capacity was set at 10,000 and scenarios were run for 1000 replicates.

\begin{tabular}{ccccc}
\hline Scenario & Description & P (surv) & HE & N \\
\hline 1 & 100 in year 1 from Bernier Island & 0.76 & 0.311 & 2094 \\
2 & 50 from Bernier Island in year 1 and year 2 & 0.79 & 0.330 & 2489 \\
3 & 50 from Bernier Island in year 1, 50 from Dorre Island in year 2 & 0.80 & 0.368 & 2251 \\
4 & 50 from Bernier Island, 50 from Dorre Island in year 1 & 0.79 & 0.362 & 2277 \\
\hline
\end{tabular}

$\mathrm{P}$ (surv): mean probability of survival; $\mathrm{HE}=$ mean expected heterozygosity using empirical estimates of allele frequencies to determine starting heterozygosities; $\mathrm{N}$ : final mean population size of extant populations.

Simulations that varied drought frequency indicated the likelihood of an appreciable impact on the survival probability of a translocated population after 50 calendar years, dropping from $100 \%$ under the assumption of no drought, to $79 \%$ with a realistic drought frequency of 1 in 6.25 years, and $58 \%$ with a drought frequency of 1 in 5 years (Figure 3). There was also predicted to be a profound effect on the final $\mathrm{N}$, as predicted carrying capacity (set to 10,000) was reached with no drought, whereas final $\mathrm{N}$ was estimated at 2277 individuals with a 1 in 6.25-year drought and 1064 at 1 in 5 years (Figure 3). 

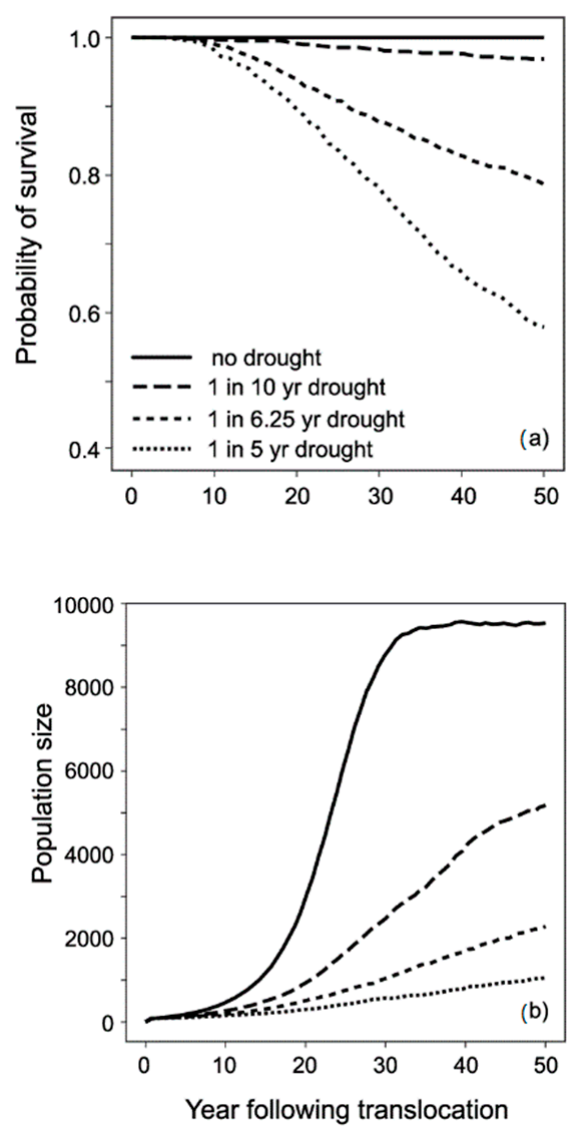

Figure 3. Performance over 50 years for 100 translocated L. fasciatus to DHI with drought frequencies of 1 in 5 years, 1 in 6.25 years, 1 in 10 years, or no drought. (a) Survival probability. (b) Population size.

Simulation of translocations recently conducted by management agencies between 2017 and 2018-harvesting Bernier and Dorre Islands for translocation to Dirk Hartog Island, and concurrent harvesting of Bernier, Dorre, and Faure Islands for translocation to Mount Gibson-including the impacts of 1 in 6.25-year droughts, predicted good survival probabilities over 50 years for the translocated populations of $83 \%$ and $84 \%$, respectively. This result was also achieved even if harvesting occurred with a reduction in the size of source populations following drought (Table 6). In contrast, the timing of harvesting had a more significant effect on the source populations. Harvesting at current census population sizes $(\mathrm{Nc})$ resulted in high survival probabilities $(99 \%, 98 \%$, and $93 \%$ for Bernier, Dorre, and Faure Islands, respectively; Table 6), assuming Faure Island to have a carrying capacity (K) of 1000 . Bernier and Dorre Island population sizes stabilise at $\sim 82 \%$ of current estimates, whereas the Faure Island population stabilises after $\sim 65 \%$ growth from current estimates to a census size of around 500. If harvesting were to occur immediately after a drought, predicted survival probabilities reduced after 50 calendar years, most markedly to $60 \%$ on Faure Island, and there was a further reduction in predicted Nc in Bernier and Dorre Island populations to around $74 \%$ of current estimates, whereas growth on Faure Island was limited to $29 \%$ (Nc 386 ). Interestingly, when Faure Island was assumed to have a $\mathrm{K}$ of 3000 , there was little improvement in survival probability post-harvest if a drought census size was assumed ( $63 \%$ with K of 3000 vs. $60 \%$ with $\mathrm{K}$ of 1000$)$. However, there was a dramatic increase in predicted Nc as 1400 was reached when harvesting occurred with a non-drought Nc and 900 with a drought impacted Nc, compared to 495 and 386 with a K of 1000, respectively. 
Table 6. Comparison of population viability analysis (PVA) outputs after 50 calendar years when harvesting source populations using either current conservative source census sizes, or likely source census sizes following droughts. Models are based on scenario 8, describing recent and ongoing movement of $L$. fasciatus, and assuming an average drought frequency of 1 in 6.25 years.

\begin{tabular}{|c|c|c|}
\hline & $\begin{array}{c}\text { Conservative Current Census } \\
\text { Sizes of Source Populations } \\
\mathrm{N}_{\text {Bernier }}=2000, \mathrm{~N}_{\text {Dorre }}=2000, \\
\mathrm{~N}_{\text {Faure }}=300\end{array}$ & $\begin{array}{l}\text { Census Sizes Following Drought } \\
\qquad \begin{array}{c}\mathrm{N}_{\text {Bernier }}=500, \mathrm{~N}_{\text {Dorre }}=500, \\
\mathrm{~N}_{\text {Faure }}=75\end{array}\end{array}$ \\
\hline \multicolumn{3}{|c|}{ (a) Target Populations } \\
\hline \multicolumn{3}{|c|}{ Dirk Hartog Island } \\
\hline $\mathrm{P}($ surv $)$ & 0.83 & 0.81 \\
\hline $\mathrm{N}$ & 2363 & 2436 \\
\hline $\mathrm{HE}$ & 0.367 & 0.367 \\
\hline \multicolumn{3}{|c|}{ Mount Gibson } \\
\hline $\mathrm{P}($ surv$)$ & 0.84 & 0.84 \\
\hline $\mathrm{N}$ & 1600 & 1565 \\
\hline $\mathrm{HE}$ & 0.372 & 0.372 \\
\hline \multicolumn{3}{|l|}{ (b) Source Populations } \\
\hline \multicolumn{3}{|c|}{ Bernier Island } \\
\hline $\mathrm{P}($ surv $)$ & 0.99 & 0.94 \\
\hline $\mathrm{N}$ & 1640 & 1474 \\
\hline HE & 0.359 & 0.353 \\
\hline \multicolumn{3}{|c|}{ Dorre Island } \\
\hline P (surv) & 0.98 & 0.95 \\
\hline $\mathrm{N}$ & 1647 & 1465 \\
\hline HE & 0.417 & 0.408 \\
\hline \multicolumn{3}{|c|}{ Faure Island * } \\
\hline $\mathrm{P}$ (surv) & $0.93 / 0.93$ & $0.60 / 0.63$ \\
\hline $\mathrm{N}$ & $495 / 1401$ & $386 / 901$ \\
\hline $\mathrm{HE}$ & $0.369 / 0.374$ & $0.344 / 0.343$ \\
\hline
\end{tabular}

$\mathrm{P}$ (surv): mean probability of survival; $\mathrm{N}$ : final mean population size of extant populations; $\mathrm{HE}=$ mean expected heterozygosity. ${ }^{*}$ Numbers to the left of the slash are for a carrying capacity of 1000 , and to the right are for a carrying capacity of 3000 . Scenarios were run for 1000 replicates.

\section{Discussion}

As the remnant range of L. fasciatus consists of just two adjacent offshore islands, the species-level impact of detrimental stochastic events affecting one or both islands could be profound. Establishing insurance populations and restoring the species to other suitable habitats free from introduced predators is a fundamental management objective, as is the retention of remnant genetic diversity to maintain adaptive capacity. While it is difficult to make conclusive summaries from the limited genetic data we provide here, we nonetheless attempt to explain observed trends that justify a more extensive genetic study. For example, our data suggest that both remnant island populations underwent genetic bottlenecks in the mid to late 1990s, potentially linked to the boom and bust cycles of L. fasciatus that occur in response to periodic droughts and thus a marked reduction in primary productivity [33,34]. Further, we show that the impact of past conservation actions (captive breeding and translocations) has possibly manifested in different ways in the two surviving translocated populations (Faure Island and Wadderin). Based on the limited samples available, Faure Island may be inbred due to non-random breeding but has relatively high allelic diversity, whereas Wadderin does not show signs of genetic inbreeding due to non-random breeding but may have passed through two selectively stronger bottlenecks (Bernier Island to Peron CBC, and Peron CBC to Wadderin). Our population viability and genetic modelling has revealed the importance of considering periodic fluctuations in population size when planning translocations and informed on the number of founders needed to avoid genetic bottlenecks. Taken together, these lines of evidence point to a critical need for genetic management and guidance for future translocations. 


\subsection{Genetic Diversity in Remnant Populations}

Island populations are expected to lose genetic diversity as a result of genetic drift, especially in the absence of migration (i.e., gene flow) that acts to increase allelic diversity $[75,76]$. Here, we found that genetic diversity (allelic richness and heterozygosity) of L. fasciatus on Bernier and Dorre Islands was approximately two-fold lower relative to values reported for mainland populations of other Australian marsupials [77,78], and reviewed in [79], which is unsurprising considering the low number of polymorphic markers used in this study. Interestingly, values were similar to the Shark Bay island population of another hare-wallaby, the rufous hare-wallaby (Lagorchestes hirsutus), which was measured with shared markers and also had lower diversity than its mainland counterpart [80]. We also identified extremely low effective population sizes for L. fasciatus (Table 3 ) given census sizes of 2800 for Bernier Island and 2500 for Dorre Island [32,33], leading to good agreement in Ne/Nc ratios of 0.05 and 0.07 , respectively. These estimates are several times smaller than those for other mammals, e.g., 0.2 to 0.8 reported in [81,82] and a mean of 0.75 reported in [83]. However, due to our low power to estimate $\mathrm{Ne}$ from genetic data, these trends require confirmation.

Bernier and Dorre Islands have been separated from mainland Australia for 8000 years (around 4000 generations), and from each other for around 5000 years [84,85], providing substantial opportunity for stochastic loss of allelic variation through genetic drift. The finding that around 10 remnant source population individuals (out of 130 ) were assigned with $80 \%$ or more probability to the other source population is therefore surprising. This observation could be consistent with recent gene flow, leading to migrant populations that have remained relatively isolated from the resident populations. However, this is unlikely, especially as it would have needed to have happened reciprocally. A more likely explanation is either a lack of discriminatory power in our markers, perhaps due to being developed in sister species [86], or there has been a technical issue, such as mis-labelling. Adequate sampling to properly determine genetic structure and the use of more powerful markers (e.g., single nucleotide polymorphic markers generated through next-generation sequencing), would resolve these alternative hypotheses.

\subsection{Impact of Past Translocations on Genetic Diversity}

The expected heterozygosities of either of the established translocated populations were not less than their source population (Peron CBC) or the parental population (Bernier Island). Despite describing two examples of serial translocations occurring from a single source population via a captive breeding programme, and hence providing opportunity for two bottleneck events, in only one case did we find evidence for a bottleneck-the Wadderin population translocated in 2013 with 12 founders. Wadderin was founded from the Peron CBC population, which itself was founded from Bernier Island (Figure 1d), and each translocation contributed a $2.4 \%$ and $5.7 \%$ loss of allelic diversity, culminating in a total loss from the Bernier source population of $8.1 \%$. Faure, on the other hand, did not undergo a genetic bottleneck according to our analysis, and had a relatively high allelic diversity. The high allelic diversity is surprising considering its demographic history, and we found it to be driven by the discovery of an additional allele (marker Me17), present in one individual in homozygous form. While this allele could have arisen in the translocated Faure Island population, its independent verification would benefit from expanding sampling of Faure and Bernier Islands. While we were not able to detect a genetic signal of a bottleneck in the Peron CBC population, founded by 25 individuals, this does not preclude the possibility that a bottleneck has occurred that we were not able to detect or from which the population later recovered.

Since translocations began to Faure Island, however, observed heterozygosity appears to have decreased below equilibrium expectations and inbreeding coefficients have increased, possibly due to limited dispersal and increased breeding between related animals post-translocation. Another possibility is an increase in mating success heterogeneity [78]. These factors could also have contributed to the island's notably low effective population size estimate. This is of concern, as small populations are prone to higher rates of loss of genetic variation via genetic drift, especially if inbreeding depression 
leads to lower rates of reproduction and further reductions in population size [17]. However, the apparently high inbreeding does not appear to be associated with poor health of the Faure Island population, as it is well established with ongoing recruitment [87]. One explanation for this apparent paradox is that the boom and bust population cycles characteristic of Shark Bay L. fasciatus populations have led to a purging of lethal alleles, negating any detrimental effect of inbreeding [34]. A more prosaic explanation is that the Faure Island sampling cohort was both small $(n=10)$ and consists of a disproportionately high number of related individuals, leading to an overestimate of the inbreeding coefficient. A more comprehensive genetic analysis and a future study of the social dynamics of the Faure Island population could resolve this uncertainty.

While our bottleneck results require independent replication, a lack of bottleneck signal for the Peron $C B C$ population with 25 founders supports results from our allele retention modelling. We show that a $70 \%$ probability of retaining a low frequency allele is maintained with a founder size of 25 , but that retention probabilities drop dramatically with founder sizes less than 20. Other populations that have passed through bottlenecks tend to have greater founder numbers. For example, in birds, a bottleneck occurred when the Hawaiian gallinule (Gallinula galeata sandvicensis) was reduced to approximately 60 individuals [88], and reductions to 100 individuals may be sufficient to observe bottleneck effects in other avian species [89]. In the Maud Island frog (Leiopelma pakeka), simulations indicate that a sustained increase in irreversible allele loss begins when populations are reduced to 140 [90]. The apparent low power to detect genetic bottlenecks in translocated L. fasciatus populations could reflect relatively small changes in allelic diversity between source and founder populations (due to low effective population sizes and genetic variation in the source), compounded by our small panel of only moderately polymorphic markers. Further, the relatively rapid demographic recovery inherent to L. fasciatus during the boom phase of natural population cycles could mask any bottleneck signal that depends on heterozygosity excess [62]. Therefore, ongoing monitoring, including genetic monitoring, of translocated populations during their establishment would provide useful data with which to detect any detrimental genetic effects that might be initially masked.

\subsection{Towards an Optimal Translocation Protocol for L. fasciatus}

A clear trade-off exists in conservation translocation programmes between maximising viability of a new population and minimising the negative impact on critical source populations [90]. For example, sufficient founders are required to ensure a translocated population is buffered from some post-establishment mortality, as well as to retain rare alleles that bolster evolutionary potential $[67,90]$. Smaller founder numbers, on the other hand, reduce any negative impacts on source populations, but translocated populations will be more sensitive to mortality and the loss of rare alleles. Our PVA models for L. fasciatus show that for newly translocated populations, survival probabilities increase with increasing founder number until this relationship asymptotes at around 120 individuals, and the release of 100 individuals ensures good growth and survival in a hypothetical haven (island or fenced sanctuary with a carrying capacity of 10,000). That carrying capacity did not significantly impact 50-year predicted survival probabilities for the Faure Island population when using reduced drought-influenced census sizes, indicates the sensitivity of the successful establishment of L. fasciatus translocated populations to the founder number, and suggests that sufficient numbers are required to withstand regular population reduction caused by stochastic events. Importantly, harvesting the numbers recommended here has no apparent impact on the critical source populations, either in terms of population growth or survival probability over a 50-year period.

Our allele retention models predict that 80 founders are needed to retain $95 \%$ of low-frequency alleles, noting that retaining 90 or $95 \%$ genetic variation are recommended minimum thresholds for maintaining the evolutionary potential of populations $[17,91]$. Hence, aggregating the results of both modelling processes suggests that at least 100 individual founder animals are needed to maximise viability and retention of allelic diversity, a comparable figure to other taxa (e.g., 120 in frogs [90], 60 to 120 in passerines [19]). Further, by simulating the effects of periodic drought on population 
growth and survival, we have provided predictions about when best to translocate. For example, if harvesting were to occur immediately after a drought, we predict a $10-22 \%$ reduction in the census size of the source population after 50 years, relative to harvesting when populations are at their peak. In turn, we predicted that 140 founders would be required to retain $95 \%$ of alleles with a population frequency of 0.05 in a new population under drought conditions (as opposed to 80 founders under no drought); a $75 \%$ increase in the number harvested from the critical source populations. Therefore, climatic cycles appear to be an important consideration in translocation programmes, and we advise that the movement of animals should occur outside periods of low rainfall and when populations have recovered demographically from their impacts.

One way to increase genetic diversity of species that exist as only small and genetically depauperate remnants is to manage the species as a metapopulation [92]. However, whether to combine genetically distinct populations is contentious [1,7,78,93-95]. While there is an immediate and obvious benefit of maximising genetic diversity and heterozygosity, thereby reducing the chance of inbreeding depression, mixing comes with risks, including outbreeding depression [1]. For example, if source populations derive from different habitats or climates, and have been long isolated, local adaptation can cause the rise of locally adapted alleles and for gene complexes to be in gametic disequilibrium. Locally adapted alleles can be diluted and gametic associations can be broken by recombination after mixing between differently adapted individuals, resulting in hybrid individuals with low fitness [96-99]. Other risks include competition for resources when there are morphological and size differences between source populations, and behavioural differences could affect mate choice, potentially reducing Ne and leading to a bias in representation of future generations (e.g., as occurs in the boodie Bettongia lesueur, [78]). Here, however, the habitats of the two adjacent $L$. fasciatus source populations have been similar across the 4000-5000 years (approx. 2000 generations) of their separation [79]. Further, there are no known differences in size, morphology, or mating behavior between islands, suggesting a low probability of outbreeding depression [95]. Considering the overall low genetic diversity maintained in this species, and by mixing we achieve a 10-12\% increase in HE of the recipient population compared to using only Bernier Island as a source population, we advocate mixing the two source island populations in future translocations and predict a low risk of any adverse consequences.

\section{Conclusions}

Our work shows how an integrated analysis of genetics and population modelling can be used to inform management planning by simulating sensitive trade-offs involved in translocating threatened species. While much work has been done on the numbers of founders needed to establish new populations, less is known about the impact of harvesting for translocations on source populations [89], which is highly relevant for species with few remnant populations remaining. We suggest that the optimal translocation protocol for L. fasciatus is to mix the Bernier and Dorre Island populations in the same year, harvesting 60 individuals from each island source population (total $n=120$ ). This gives a good probability of retaining low-frequency private alleles from each island, maximises survival probability and heterozygosity of translocated populations, limits logistical cost, and, crucially, has no major impact on the source populations. As the translocations currently underway to Dirk Hartog Island and Mt. Gibson approximate these recommendations, it will be valuable to monitor these populations over time to compare performance to model predictions. It is also worth considering Faure Island as an alternative source population to Bernier Island for future translocations, as was done with the Mt. Gibson translocation, to relieve pressure on one of the two remnant wild populations. However, in addition to possible inbreeding, our modelling shows Faure Island is more sensitive to stochastic events due to a smaller census population, further compounded if its carrying capacity is less than Bernier and Dorre Islands, and so the PVA models developed here should be used to assess the impact of any future harvesting. Wherever feasible, and after consideration of potential over-harvesting, future supplementations of the established translocated populations on Faure Island and Wadderin Sanctuary should derive from Dorre Island which, as a genetic mixing event, would 
be expected to increase gene diversity of the recipient population. Further, Dorre Island has a higher heterozygosity, more private alleles and lower inbreeding than Bernier Island. Finally, while we show that $L$. fasciatus seems resilient to harvesting and is well suited to translocation programmes, including multiple harvests from source populations, regular droughts, and limited carrying capacity, which have a substantial impact on population viability, particularly for populations with census sizes less than 500. We recommend that translocations are avoided during extended periods of drought and subsequent demographic recovery, due to a notably lower growth rate of the source populations after harvesting, and reduced capacity of new populations to retain allelic diversity.

Supplementary Materials: The following are available online at http://www.mdpi.com/1424-2818/12/12/448/s1, Spreadsheet S1: Genetic samples; Table S1: PCR multiplexes; Table S2: Details and justification of the demographic parameters used in ALLELERETAIN; Table S3: Details and justification of the demographic parameters used in VORTEX; Table S4: Performance of seven polymorphic microsatellite markers; Table S5: Population pairwise FSTs and probability values; Table S6: Comparing allelic richness with and without marker Me17; Table S7a-d: Summary of PVA outputs for translocation scenarios; Figure S1: Pairwise relatedness; Figure S2: Temporal change in genetic diversity for the two remnant source populations.

Author Contributions: Conceptualization, N.J.M., K.O. and D.J.W.; formal analysis, D.J.W.; investigation, D.J.W. and K.O.; resources, K.O., P.B.S.S., M.S., C.S. and J.S.; data curation, K.O. and P.B.S.S.; writing-original draft preparation, D.J.W.; writing—review and editing, N.J.M., K.O., J.S., P.B.S.S., M.S., C.S. and D.J.W.; visualization, N.J.M. and D.J.W.; project administration, D.J.W. and N.J.M.; funding acquisition, N.J.M. and K.O. All authors have read and agreed to the published version of the manuscript.

Funding: This research was supported by the Australian Government's National Environmental Science Program through the Threatened Species Recovery Hub.

Acknowledgments: We thank Keith Morris and Manda Page for comments on earlier versions of the manuscript, John Kanowski for valuable comments on late versions of the manuscript, Mark Eldridge, Anthony Friend, and Mia Hillyer for help with conceptualisation, Saul Cowen for discussion on translocation strategies, Laura Ruykus and Kim Branch for collection of samples, and Shelley McArthur for assistance in the laboratory. The authors would also like to thank three anonymous reviewers for their helpful comments.

Conflicts of Interest: The authors declare that they have no conflict of interest.

\section{References}

1. Frankham, R.; Ballou, J.D.; Ralls, K.; Eldridge, M.D.B.; Dudash, M.R.; Fenster, C.B.; Lacy, R.C.; Sunnucks, P. Genetic Management of Fragmented Animal and Plant Populations; Oxford University Press: Oxford, UK, 2017; p. 432.

2. Fischer, J.; Lindenmayer, D.B. An assessment of the published results of animal relocations. Biol. Conserv. 2000, 96, 1-11. [CrossRef]

3. Germano, J.M.; Bishop, P.J. Suitability of Amphibians and Reptiles for Translocation. Conserv. Biol. 2009, 23, 7-15. [CrossRef] [PubMed]

4. Ottewell, K.; Dunlop, J.; Thomas, N.; Morris, K.; Coates, D.; Byrne, M. Evaluating success of translocations in maintaining genetic diversity in a threatened mammal. Biol. Conserv. 2014, 171, 209-219. [CrossRef]

5. Perez, I.; Anadon, J.D.; Diaz, M.; Nicola, G.G.; Tella, J.L.; Gimenez, A. What is wrong with current translocations? A review and a decision-making proposal. Front. Ecol. Environ. 2012, 10, 494-501. [CrossRef]

6. Sheean, V.A.; Manning, A.D.; Lindenmayer, D.B. An assessment of scientific approaches towards species relocations in Australia. Austral Ecol. 2012, 37, 204-215. [CrossRef]

7. Weeks, A.R.; Sgro, C.M.; Young, A.G.; Frankham, R.; Mitchell, N.J.; Miller, K.A.; Byrne, M.; Coates, D.J.; Eldridge, M.D.B.; Sunnucks, P.; et al. Assessing the benefits and risks of translocations in changing environments: A genetic perspective. Evol. Appl. 2011, 4, 709-725. [CrossRef]

8. Short, J. Predation by feral cats key to the failure of a long-term reintroduction of the western barred bandicoot (Perameles bougainville). Wildl. Res. 2016, 43, 38-50. [CrossRef]

9. Brashares, J.S.; Werner, J.R.; Sinclair, A.R.E. Social 'meltdown' in the demise of an island endemic: Allee effects and the Vancouver Island marmot. J. Anim. Ecol. 2010, 79, 965-973. [CrossRef] [PubMed]

10. IUCN/SSC. Guidelines for Reintroductions and Other Conservation Translocations; Version 1.0; IUCN Special Survival Commission: Gland, Switzerland; p. viiii + 57. 
11. Saltz, D. A long-term systematic approach to planning reintroductions: The Persian fallow deer and the Arabian oryx in Israel. Anim. Conserv. 1998, 1, 245-252. [CrossRef]

12. Holzapfel, S.A.; Robertson, H.A.; McLennan, J.A.; Sporle, W.; Hackwell, K.; Impey, M. Kiwi (Apteryx spp.) recovery plan 2008-2018. In Threatened Species Recovery Plan; Department of Conservation: Wellington, New Zealand, 2008; Volume 60.

13. Lloyd, B.D.; Powlesland, R.G. The decline of kakapo (Strigops habroptilus) and attempts at conservation by translocation. Biol. Conserv. 1994, 69, 75-85. [CrossRef]

14. Weeks, A.R.; Heinze, D.; Perrin, L.; Stoklosa, J.; Hoffmann, A.A.; van Rooyen, A.; Kelly, T.; Mansergh, I. Genetic rescue increases fitness and aids rapid recovery of an endangered marsupial population. Nat. Comm. 2017, 8, 1-6. [CrossRef] [PubMed]

15. Frankham, R. Genetics and extinction. Biol. Conserv. 2005, 126, 131-140. [CrossRef]

16. Allendorf, F.W. Genetic Drift and the Loss of Alleles Versus Heterozygosity. Zoo Biol. 1986, 5, 181-190. [CrossRef]

17. Gilpin, M.E.; Soule, M.E. Minimum viable populations: Processes of species extinction. In Conservation Biology: The Science of Scarcity and Diversity; Gilpin, M.E., Soule, M.E., Eds.; Sinauer: Sunderland, MA, USA, 1986; pp. 19-24.

18. Lacy, R.C. Lessons from 30 years of population viability analysis of wildlife populations. Zoo Biol. 2019, 38, 67-77. [CrossRef]

19. Tracy, L.N.; Wallis, G.P.; Efford, M.G.; Jamieson, I.G. Preserving genetic diversity in threatened species reintroductions: How many individuals should be released? Anim. Conserv. 2011, 14, 439-446. [CrossRef]

20. Pacioni, C.; Wayne, A.F.; Page, M. Guidelines for genetic management in mammal translocation programs. Biol. Conserv. 2019, 237, 105-113. [CrossRef]

21. Grueber, C.E.; Fox, S.; McLennan, E.A.; Gooley, R.M.; Pemberton, D.; Hogg, C.J.; Belov, K. Complex problems need detailed solutions: Harnessing multiple data types to inform genetic management in the wild. Evol. Appl. 2019, 12, 280-291. [CrossRef]

22. Kelly, E.; Phillips, B. How many and when? Optimising targeted gene flow for a step change in the environment. Ecol. Lett. 2019, 22, 447-457. [CrossRef]

23. Ramalho, C.E.; Ottewell, K.M.; Chambers, B.K.; Yates, C.J.; Wilson, B.A.; Bencini, R.; Barrett, G. Demographic and genetic viability of a medium-sized ground-dwelling mammal in a fire prone, rapidly urbanizing landscape. PLoS ONE 2018, 13, e0191190. [CrossRef]

24. Woinarski, J.C.Z.; Burbidge, A.A.; Harrison, P.L. Ongoing unraveling of a continental fauna: Decline and extinction of Australian mammals since European settlement. Proc. Natl. Acad. Sci. USA 2015, 112, 4531-4540. [CrossRef]

25. Burbidge, A.A.; McKenzie, N.L. Patterns in the Modern Decline of Western-Australia Vertebrate Fauna-Causes and Conservation Implications. Biol. Conserv. 1989, 50, 143-198. [CrossRef]

26. Cardillo, M.; Bromham, L. Body size and risk of extinction in Australian mammals. Conserv. Biol. 2001, 15, 1435-1440. [CrossRef]

27. Chisholm, R.; Taylor, R. Null-hypothesis significance testing and the critical weight range for Australian mammals. Conserv. Biol. 2007, 21, 1641-1645. [CrossRef] [PubMed]

28. Woinarski, J.C.Z. Critical-weight-range marsupials in northern Australia are declining: A commentary on Fisher et al. (2014) 'The current decline of tropical marsupials in Australia: Is history repeating?'. Glob. Ecol. Biogeogr. 2015, 24, 118-122. [CrossRef]

29. Molloy, S.W.; Davis, R.A.; Van Etten, E.J.B. Species distribution modelling using bioclimatic variables to determine the impacts of a changing climate on the western ringtail possum (Pseudocheirus occidentals; Pseudocheiridae). Environ. Conserv. 2014, 41, 176-186. [CrossRef]

30. Reckless, H.J.; Murray, M.; Crowther, M.S. A review of climatic change as a determinant of the viability of koala populations. Wildl. Res. 2017, 44, 458-470. [CrossRef]

31. Shortridge, G.C. An account of the geographical distribution of the Marsuprals and Monotremes of South-West Australia, having special reference to the specimens collected during the Balston Expedition of 1904-1907. Proc. Zool. Soc. Lond. 1909, 1909, 803-848.

32. Thomas, N.; (Department of Biodiversity, Conservation and Attractions, Perth, WA, Australia). Personal communication, 2018. 
33. Chapman, T.F.; Sims, C.; Thomas, N.D.; Reinhold, L. Assessment of mammal populations on Bernier and Dorre Island 2006-2013. In Report for the Department of Parks and Wildlife; Department of Parks and Wildlife: Kensington, Australia, 2015; p. 56.

34. Short, J.; Turner, B.; Majors, C.; Leone, J. The fluctuating abundance of endangered mammals on Bernier and Dorre Islands, Western Australia-conservation implications. Aust. Mammal. 1997, 20, 53-61.

35. Hardman, B.; Moro, D.; Calver, M. Direct evidence implicates feral cat predation as the primary cause of failure of a mammal reintroduction programme. Ecol. Manag. Restor. 2016, 17, 152-158. [CrossRef]

36. Morris, K.; Sims, C.; Himbeck, K.; Christensen, P.; Sercombe, N.; Ward, B.; Noakes, N. Project Eden-fauna recovery on Peron Peninsula, Shark Bay: Western Shield review-February 2003. Conserv. Sci. West. Aust. 2004, 5, 202-234.

37. Short, J.; Turner, B. The Distribution and Abundance of the Banded and Rufous Hare-Wallabies, Lagostrophus fasciatus and Lagorchestes hirsutus. Biol. Conserv. 1992, 60, 157-166. [CrossRef]

38. Ruykys, L.; Smith, M.; Kanowski, J. Translocation of Banded Hare-wallabies (Lagostrophus fasciatus) to Mt Gibson Sanctuary and Faure Island, WA; Department of Biodiversity, Conservation and Attractions: Kensington, Australia, 2017; p. 44.

39. Short, J.; Hide, A. Successful reintroduction of the brushtail possum to Wadderin Sanctuary in the eastern wheatbelt of Western Australia. Aust. Mammal. 2014, 36, 229-241. [CrossRef]

40. Short, J.; (Wildlife Research and Management Pty Ltd., Perth, WA, Australia). Personal communication, 2020.

41. Morris, K.; Page, M.; Thomas, N.; Ottewell, K. A strategic framework for the reconstruction and conservation of the vertebrate fauna of Dirk Hartog Island 2016-2030; Department of Parks and Wildlife: Perth, Australia, 2017; p. 26.

42. Harris, R.M.B.; Beaumont, L.J.; Vance, T.R.; Tozer, C.R.; Remenyi, T.A.; Perkins-Kirkpatrick, S.E.; Mitchell, P.J.; Nicotra, A.B.; McGregor, S.; Andrew, N.R.; et al. Biological responses to the press and pulse of climate trends and extreme events. Nat. Clim. Chang. 2018, 8, 579-587. [CrossRef]

43. Sunnucks, P.; Hales, D.F. Numerous transposed sequences of mitochondrial cytochrome oxidase I-II in aphids of the genus Sitobion (Hemiptera: Aphididae). Mol. Biol. Evol. 1996, 13, 510-524. [CrossRef]

44. Taylor, A.C.; Cooper, D.W. A set of tammar wallaby (Macropus eugenii) microsatellites tested for genetic linkage. Mol. Ecol. 1998, 7, 925-926.

45. Pope, L.C.; Sharp, A.; Moritz, C. Population structure of the yellow-footed rock-wallaby Petrogale xanthopus (Gray, 1854) inferred from mtDNA sequences and microsatellite loci. Mol. Ecol. 1996, 5, 629-640. [CrossRef]

46. Spencer, P.B.S.; Odorico, D.M.; Jones, S.J.; Marsh, H.D.; Miller, D.J. Highly Variable Microsatellites in Isolated Colonies of the Rock-Wallaby (Petrogale assimilis). Mol. Ecol. 1995, 4, 523-525. [CrossRef]

47. Rousset, F. GENEPOP ' 007: A complete re-implementation of the GENEPOP software for Windows and Linux. Mol. Ecol. Resour. 2008, 8, 103-106. [CrossRef]

48. Guo, S.W.; Thompson, E.A. Performing the exact test of hardy-weinberg proportion for multiple alleles. Biometrics 1992, 48, 361-372. [CrossRef]

49. Van Oosterhout, C.; Hutchinson, W.F.; Wills, D.P.M.; Shipley, P. MICRO-CHECKER: Software for identifying and correcting genotyping errors in microsatellite data. Mol. Ecol. Notes 2004, 4, 535-538. [CrossRef]

50. Pritchard, J.K.; Stephens, M.; Donnelly, P. Inference of population structure using multilocus genotype data. Genetics 2000, 155, 945-959. [PubMed]

51. Evanno, G.; Regnaut, S.; Goudet, J. Detecting the number of clusters of individuals using the software STRUCTURE: A simulation study. Mol. Ecol. 2005, 14, 2611-2620. [CrossRef] [PubMed]

52. Kopelman, N.M.; Mayzel, J.; Jakobsson, M.; Rosenberg, N.A.; Mayrose, I. Clumpak: A program for identifying clustering modes and packaging population structure inferences across K. Mol. Ecol. Res. 2015, 15, 1179-1191. [CrossRef] [PubMed]

53. Rosenberg, N.A. DISTRUCT: A program for the graphical display of population structure. Mol. Ecol. Notes 2004, 4, 137-138. [CrossRef]

54. Peakall, R.; Smouse, P. GenAlEx 6.5: Genetic analysis in Excel. Population genetic software for teaching and research-An update. Bioinformatics 2012, 28, 2537-2539. [CrossRef] [PubMed]

55. Peakall, R.; Smouse, P.E. GENALEX 6: Genetic analysis in Excel. Population genetic software for teaching and research. Mol. Ecol. Notes 2006, 6, 288-295. [CrossRef]

56. Kalinowski, S.T. HP-RARE 1.0: A computer program for performing rarefaction on measures of allelic richness. Mol. Ecol. Notes 2005, 5, 187-189. [CrossRef] 
57. Hill, W.G. Estimation of Effective Population-Size from Data on Linkage Disequilibrium. Genet. Res. 1981, 38, 209-216. [CrossRef]

58. Waples, R.S. A bias correction for estimates of effective population size based on linkage disequilibrium at unlinked gene loci. Conserv. Genet. 2006, 7, 167-184. [CrossRef]

59. Waples, R.S.; Do, C. Linkage disequilibrium estimates of contemporary Ne using highly variable genetic markers: A largely untapped resource for applied conservation and evolution. Evol. Appl. 2010, 3, 244-262. [CrossRef]

60. Do, C.; Waples, R.S.; Peel, D.; Macbeth, G.M.; Tillett, B.J.; Ovenden, J.R. NEESTIMATOR v2: Re-implementation of software for the estimation of contemporary effective population size (Ne) from genetic data. Mol. Ecol. Res. 2014, 14, 209-214. [CrossRef]

61. Piry, S.; Luikart, G.; Cornuet, J.M. BOTTLENECK: A computer program for detecting recent reductions in the effective population size using allele frequency data. J. Hered. 1999, 90, 502-503. [CrossRef]

62. Cornuet, J.M.; Luikart, G. Description and power analysis of two tests for detecting recent population bottlenecks from allele frequency data. Genetics 1996, 144, 2001-2014.

63. Luikart, G.; Sherwin, W.B.; Steele, B.M.; Allendorf, F.W. Usefulness of molecular markers for detecting population bottlenecks via monitoring genetic change. Mol. Ecol. 1998, 7, 963-974. [CrossRef]

64. Luikart, G.; Allendorf, F.W.; Cornuet, J.M.; Sherwin, W.B. Distortion of allele frequency distributions provides a test for recent population bottlenecks. J. Hered. 1998, 89, 238-247. [CrossRef]

65. Queller, D.C.; Goodnight, K.F. Estimating Relatedness Using Genetic-Markers. Evolution 1989, 43, $258-275$. [CrossRef]

66. Weiser, E.L.; Grueber, C.E.; Jamieson, I.G. AlleleRetain: A program to assess management options for conserving allelic diversity in small, isolated populations. Mol. Ecol. Res. 2012, 12, 1161-1167. [CrossRef]

67. Weiser, E.L.; Grueber, C.E.; Jamieson, I.G. Simulating Retention of Rare Alleles in Small Populations to Assess Management Options for Species with Different Life Histories. Conserv. Biol. 2013, 27, 335-344. [CrossRef]

68. R Core Team. R: A Language and Environment for Statistical Computing; R Foundation for Statistical Computing: Vienna, Austria, 2019; Available online: https://www.R-project.org/ (accessed on 11 May 2019).

69. Sims, C.; (Department of Biodiversity, Conservation and Attractions, Perth, WA, Australia). Personal communication, 2018.

70. Richards, J.D.; Short, J.; Prince, R.I.T.; Friend, J.A.; Courtenay, J.M. The biology of banded (Lagostrophus fasciatus) and rufous (Lagorchestes hirsutus) hare-wallabies (Diprotodontia: Macropodidae) on Dorre and Bernier Islands, Western Australia. Wildl. Res. 2001, 28, 311-322. [CrossRef]

71. Lacy, R.C. VORTEX-A computer-simulation model for population viability analysis. Wildl. Res. 1993, 20, 45-65. [CrossRef]

72. Lacy, R.C.; Pollak, J.P. Vortex: A Stochastic Simulation of the Extinction Process; Version 10.2.9; Chicago Zoological Society: Brookfield, IL, USA, 1993; Available online: http://www.vortex10.org/Vortex10.aspx (accessed on 11 May 2019).

73. Eldridge, M.D.B.; King, J.M.; Loupis, A.K.; Spencer, P.B.S.; Taylor, A.C.; Pope, L.C.; Hall, G.P. Unprecedented low levels of genetic variation and inbreeding depression in an island population of the black-footed rock-wallaby. Conserv. Biol. 1999, 13, 531-541. [CrossRef]

74. Chapuis, M.P.; Estoup, A. Microsatellite null alleles and estimation of population differentiation. Mol. Biol. Evol. 2007, 24, 621-631. [CrossRef] [PubMed]

75. Frankham, R. Do island populations have less genetic variation than mainland populations? Heredity 1997, 78, 311-327. [CrossRef] [PubMed]

76. Wright, S. Evolution in Mendelian populations. Genetics 1931, 16, 0097-0159.

77. Pacioni, C.; Wayne, A.F.; Spencer, P.B.S. Genetic outcomes from the translocations of the critically endangered woylie. Curr. Zool. 2013, 59, 294-310. [CrossRef]

78. Thavornkanlapachai, R.; Mills, H.R.; Ottewell, K.; Dunlop, J.; Sims, C.; Morris, K.; Donaldson, F.; Kennington, W.J. Mixing Genetically and Morphologically Distinct Populations in Translocations: Asymmetrical Introgression in A Newly Established Population of the Boodie (Bettongia lesueur). Genes 2019, 10, 729. [CrossRef]

79. Smith, S.; Hughes, J. Microsatellite and mitochondrial DNA variation defines island genetic reservoirs for reintroductions of an endangered Australian marsupial, Perameles bougainville. Conserv. Genet. 2008, 9, 547-557. [CrossRef] 
80. Eldridge, M.D.B.; Neaves, L.E.; Spencer, P.B.S. Genetic analysis of three remnant populations of the rufous hare-wallaby (Lagorchestes hirsutus) in arid Australia. Aust. Mammal. 2019, 41, 123-131. [CrossRef]

81. Frankham, R. Effective Population Size Adult Population Size Ratios in Wildlife-A Review. Genet. Res. 1995, 66, 95-107. [CrossRef]

82. Nunney, L. The influence of variation in female fecundity on effective population size. Biol. J. Linn. Soc. 1996, 59, 411-425. [CrossRef]

83. Waples, R.S.; Luikart, G.; Faulkner, J.R.; Tallmon, D.A. Simple life-history traits explain key effective population size ratios across diverse taxa. Proc. R. Soc. B Biol. Sci. 2013, 280. [CrossRef] [PubMed]

84. Churchill, D.M. Late Quaternary eustatic changes in the Swan River district. J. R. Soc. West. Aust. 1959, 42, 53-55.

85. Short, J.; Turner, B.; Majors, C. The Distribution, Relative Abundance, and Habitat Preferences of Rare Macropods and Bandicoots on Barrow, Boodie, Bernier and Dorre Islands; CSIRO Division of Wildlife and Ecology: Midland, Australia, 1989; p. 64.

86. Goldstein, D.B.; Pollock, D.D. Launching microsatellites: A review of mutation processes and methods of phylogenetic inference. J. Hered. 1997, 88, 335-342. [CrossRef] [PubMed]

87. Smith, M.; (Australian Wildlife Conservancy, Perth, WA, Australia). Personal communication, 2020.

88. Sonsthagen, S.A.; Wilson, R.E.; Underwood, J.G. Genetic implications of bottleneck effects of differing severities on genetic diversity in naturally recovering populations: An example from Hawaiian coot and Hawaiian gallinule. Ecol. Evol. 2017, 7, 9925-9934. [CrossRef] [PubMed]

89. Heber, S.; Briskie, J.V. Population Bottlenecks and Increased Hatching Failure in Endangered Birds. Conserv. Biol. 2010, 24, 1674-1678. [CrossRef]

90. Easton, L.J.; Bishop, P.J.; Whigham, P.A. Balancing act: Modelling sustainable release numbers for translocations. Anim. Conserv. 2019. [CrossRef]

91. Allendorf, F.W.; Ryman, N. The role of genetics in population viability analysis. In Population Viability Analysis; Beissinger, S.R., McCullough, D.R., Eds.; University of Chicago Press: Chicago, IL, USA, 2002; pp. 50-85.

92. Pacioni, C.; Rafferty, C.; Morley, K.; Stevenson, S.; Chapman, A.; Wickins, M.; Verney, T.; Deegan, G.; Trocini, S.; Spencer, P.B.S. Augmenting the conservation value of rehabilitated wildlife by integrating genetics and population modeling in the post-rehabilitation decision process. Curr. Zool. 2018, 64, 593-601. [CrossRef]

93. Allendorf, F.W.; Leary, R.F.; Spruell, P.; Wenburg, J.K. The problems with hybrids: Setting conservation guidelines. Trends Ecol. Evol. 2001, 16, 613-622. [CrossRef]

94. Edmands, S. Between a rock and a hard place: Evaluating the relative risks of inbreeding and outbreeding for conservation and management. Mol. Ecol. 2007, 16, 463-475. [CrossRef]

95. Frankham, R.; Ballou, J.D.; Eldridge, M.D.B.; Lacy, R.C.; Ralls, K.; Dudash, M.R.; Fenster, C.B. Predicting the Probability of Outbreeding Depression. Conserv. Biol. 2011, 25, 465-475. [CrossRef]

96. Armbruster, P.; Bradshaw, W.E.; Steiner, A.L.; Holzapfel, C.M. Evolutionary responses to environmental stress by the pitcher-plant mosquito, Wyeomyia smithii. Heredity 1999, 83, 509-519. [CrossRef] [PubMed]

97. Edmands, S. Heterosis and outbreeding depression in interpopulation crosses spanning a wide range of divergence. Evolution 1999, 53, 1757-1768. [CrossRef] [PubMed]

98. Marr, A.B.; Keller, L.F.; Arcese, P. Heterosis and outbreeding depression in descendants of natural immigrants to an inbred population of song sparrows (Melospiza melodia). Evolution 2002, 56, 131-142. [CrossRef] [PubMed]

99. Tymchuk, W.E.; Sundstrom, L.F.; Devlin, R.H. Growth and survival trade-offs and outbreeding depression in rainbow trout (Oncorhynchus mykiss). Evolution 2007, 61, 1225-1237. [CrossRef] [PubMed]

Publisher's Note: MDPI stays neutral with regard to jurisdictional claims in published maps and institutional affiliations. 